\title{
Context-Dependent Modulation of Excitatory Synaptic Strength by Synaptically Released Zinc
}

\author{
Bopanna I. Kalappa and ${ }^{1}$ Thanos Tzounopoulos
}

DOI:http://dx.doi.org/10.1523/ENEURO.0011-17.2017

Departments of Otolaryngology and Neurobiology, University of Pittsburgh, Pittsburgh, PA 15261

\begin{abstract}
Synaptically released zinc inhibits baseline excitatory neurotransmission; however, the role of this neuromodulator on short-term plasticity during different levels of synaptic activity remains largely unknown. This lack of knowledge prevents our understanding of information transfer across zinc-releasing synapses, including $50 \%$ of excitatory synapses in cortical areas. We used in vitro electrophysiology in mouse brain slices and discovered that the effects of zinc on excitatory postsynaptic current (EPSC) amplitudes are context-dependent. At lower frequencies of activity, synaptically released zinc reduces EPSC amplitudes. In contrast, at higher stimulation frequencies and vesicular release probability (Pr), zinc inhibits EPSC amplitudes during the first few stimuli but leads to enhanced steady-state EPSC amplitudes during subsequent stimuli. This paradoxical enhancement is due to zinc-dependent potentiation of synaptic facilitation via the recruitment of endocannabinoid signaling. Together, these findings demonstrate that synaptically released zinc is a modulator of excitatory short-term plasticity, which shapes information transfer among excitatory synapses.
\end{abstract}

Key words: auditory brainstem; auditory synapses; short-term plasticity; synaptic zinc; ZnT3

\section{Significance Statement}

In many brain areas, including the neocortex, limbic structures, and auditory brainstem, glutamatergic nerve terminals contain zinc in their synaptic vesicles. Zinc is loaded into these vesicles by zinc transporter 3 and is coreleased with glutamate. Synaptically released zinc is an inhibitory neuromodulator in excitatory synapses, but the role of zinc in short-term plasticity remains unknown. Our results suggest that zinc shapes excitatory synaptic strength in a manner dependent on frequency and activity level. Namely, during low vesicular release probability $(\mathrm{Pr})$ and low-frequency stimulation, zinc inhibits EPSCs; during higher $\operatorname{Pr}$ and prolonged presynaptic stimulation, zinc enhances steady-state EPSCs.

\section{Introduction}

Zinc is an essential element for cellular function. Divalent zinc is a cofactor in a large number of enzymes and regulatory proteins (Vallee, 1988), and as such, the chemistry and biology of zinc metalloproteins have historically dominated the field of zinc biology. However, in recent years there has been growing evidence for a signaling role of mobile chelatable zinc, which is released in tissues such as the prostate, pancreas, and brain (Frederickson et al., 2005; Kelleher et al., 2011). In the brain, the vesic-

Received January 10, 2017; accepted February 9, 2017; First published February 15, 2017.

Authors report no conflict of interest. ular zinc transporter, ZnT3, sequesters zinc into synaptic glutamatergic vesicles in many excitatory synapses. In the cortex, more than $50 \%$ of excitatory presynaptic terminals have vesicles that contain ZnT3, attesting to zinc's importance in synaptic transmission (Sindreu et al., 2003; Frederickson et al., 2005). Recent studies used novel tools for chelating and tracking zinc in central synapses and established that zinc is a phasically released inhibitory neuromodulator in excitatory synapses. In response to a single presynaptic action potential, synaptic zinc is re- 
leased from the presynaptic terminal and inhibits postsynaptic glutamate AMPA and NMDA receptor EPSCs (NMDARs/AMPARs) via postsynaptic mechanisms (Pan et al., 2011; Kalappa et al., 2015). Moreover, during brief repetitive synaptic stimulation, zinc inhibits synaptic and extrasynaptic glutamate NMDARs via postsynaptic mechanisms (Vergnano et al., 2014; Anderson et al., 2015) and is necessary-along with GPR39, a putative metabotropic zinc-sensing receptor-for activation of endocannabinoid signaling and inhibition of vesicular release probability (Pr; Perez-Rosello et al., 2013).

Zinc is released from glutamatergic vesicles and inhibits excitatory synaptic strength via pre- and postsynaptic mechanisms. Therefore, it is essential to study the mechanisms and dynamics of zinc modulation of excitatory neurotransmission during ongoing synaptic activity. The determination of these mechanisms will be crucial for understanding the role of synaptically released zinc in information transfer among excitatory synapses during different levels of synaptic activity. To study this issue, we combined electrophysiological, pharmacological, and genetic techniques.

\section{Materials and Methods}

\section{Animals}

In this study, we used male or female ICR mice (Harlan Laboratory) and ZnT3 wild-type (WT) and knockout (KO) littermate mice (Jackson Laboratory) aged from postnatal day 18 (P18) to P28. All animal procedures were approved by the Institutional Animal Care and Use Committee of the University of Pittsburgh, Pittsburgh, PA.

\section{Electrophysiology}

Brain slice preparation and electrophysiological experiments were carried out using extracellular solution artificial cerebrospinal fluid (ACSF) of the following composition (in mM): $130 \mathrm{NaCl}, 3 \mathrm{KCl}, 1.2 \mathrm{CaCl}_{2} \cdot 2 \mathrm{H}_{2} \mathrm{O}, 1.8$ $\mathrm{MgCl}_{2} \cdot 6 \mathrm{H}_{2} \mathrm{O}, 20 \mathrm{NaHCO}_{3}, 3$ Hepes, and 10 D-glucose, saturated with $95 \% \mathrm{O}_{2} / 5 \% \mathrm{CO}_{2}$ ( $\left.\mathrm{vol} / \mathrm{vol}\right), \mathrm{pH} 7.25-7.35$, $\sim 300 \mathrm{mOsm}$. To minimize changes in excitability of parallel fibers when switching ACSFs, divalent ion concentrations were optimized as follows: $1.2 \mathrm{~mm}$ external calcium ACSF consisted of $1.2 \mathrm{~mm} \mathrm{CaCl}$ and $1.8 \mathrm{~mm}$ $\mathrm{MgCl}_{2}$, and $2.4 \mathrm{~mm}$ external calcium ACSF consisted of $2.4 \mathrm{mM} \mathrm{CaCl}{ }_{2}$ and $0.6 \mathrm{mM} \mathrm{MgCl}_{2}$. Contaminating zinc was removed from the ACSF by stirring the ACSF with Chelex 100 resin (Bio-Rad) for $1 \mathrm{~h}$. High-purity $\mathrm{CaCl}_{2} \cdot 2 \mathrm{H}_{2} \mathrm{O}$ and $\mathrm{MgCl}_{2} \cdot 6 \mathrm{H}_{2} \mathrm{O}$ salts (99.995\% purity; Sigma-Aldrich) were added to the ACSF after the Chelex resin was filtered

(TT) and T32DC011499 (BIK).

Acknowledgments: We thank Dr. Elias Aizenman for helpful discussions and critical reading of the manuscript.

Correspondence should be addressed to Thanos Tzounopoulos, Department of Otolaryngology, University of Pittsburgh, Biomedical Science Tower 3, Room 3017, 3501 Fifth Avenue, Pittsburgh, PA 15261. E-mail: thanos@pitt.edu.

DOl:http://dx.doi.org/10.1523/ENEURO.0011-17.2017

Copyright $\odot 2017$ Kalappa and Tzounopoulos

This is an open-access article distributed under the terms of the Creative Commons Attribution 4.0 International, which permits unrestricted use, distribution and reproduction in any medium provided that the original work is properly attributed. using Nalgene rapid-flow filters lined with polyethersulfone (0.2- $\mu \mathrm{m}$ pore size). All plastic and glassware used in these experiments were washed with $5 \%$ high-purity nitric acid. For brain slice preparations, mice were first anesthetized with isoflurane (3\%) and then immediately decapitated. Brains were rapidly removed, and coronal slices $(210 \mu \mathrm{m})$ of the left dorsal cochlear nucleus (DCN) were prepared in $1.2 \mathrm{~mm}$ external calcium containing ACSF at $35^{\circ} \mathrm{C}$ using a Vibratome (VT1200 S; Leica). Slices were then transferred to a holding chamber, where they were incubated for $\sim 60 \mathrm{~min}$ at $35^{\circ} \mathrm{C}$. After incubation, slices were maintained at room temperature and used for experiments up to a duration of $4 \mathrm{~h}$. For electrophysiological experiments, slices were transferred into the recording chamber and perfused with ACSF at a rate of $1-2 \mathrm{ml} / \mathrm{min}$. Cartwheel cells in the molecular layer of the DCN were identified by their characteristic firing pattern that consists of simple and complex spikes (Zhang and Oertel, 1993; Manis et al., 1994; Tzounopoulos et al., 2004). Electrophysiological recordings were made using a MultiClamp700B amplifier equipped with Digidata-1440A A/D converter (Molecular Devices). Whole-cell voltage-clamp recordings were conducted at $-40 \mathrm{mV}$ holding potential, except for Figs. 1 and 6, where neurons were held at -70 $\mathrm{mV}$. For whole-cell recordings, we used borosilicate firepolished glass pipettes with filament (Sutter Instruments). Recording pipettes were filled with a cesium-based internal solution with the following composition (in $\mathrm{mM}$ ): 126 $\mathrm{CsCH}_{3} \mathrm{O}_{3} \mathrm{~S}, 4 \mathrm{KCl}, 10$ Hepes, $4 \mathrm{Na}_{2} \mathrm{ATP}, 0.3$ Tris-GTP, 10 Tris-phosphocreatine, $1 \mathrm{Cs}_{2}$ EGTA, $1 \mathrm{QX}-314$, and 3 sodium ascorbate ( $\mathrm{pH} 7.25,295 \mathrm{mOsm}), 3-5 \mathrm{M} \Omega$ resistance. Experimental results reported in Figs. 1 and 6 were conducted using a $\mathrm{K}$-based internal solution containing (in mM) 113 K-gluconate, $4.5 \quad \mathrm{MgCl}_{2} \cdot 6 \mathrm{H}_{2} \mathrm{O}, 14$ Trisphosphocreatine, 9 Hepes, 0.1 EGTA, $4 \mathrm{Na}_{2}$ ATP, 0.3 Tris-GTP, and 10 sucrose (pH 7.3, 300 mOsm). Recordings were conducted at $34-37^{\circ} \mathrm{C}$ using an inline heating system. Electrode series resistance was compensated at $70 \%-80 \%$ on-line using a $10-\mu$ s lag. Data were sampled at 10 or $20 \mathrm{kHz}$ and filtered at 4 or $8 \mathrm{kHz}$. AMPA EPSCs in cartwheel cells were evoked by stimulating parallel fibers with an Isoflex stimulator (AMPI) using ACSF containing glass theta electrodes. AMPA EPSC peak amplitudes were measured from the baseline obtained by extrapolating the decay of the preceding AMPA EPSC using a single-exponential function. All experiments were conducted in the presence of glycine and $\mathrm{GABA}_{\mathrm{A}}$ receptor blockers, strychnine $(1 \mu \mathrm{M})$, and SR95531 $(20 \mu \mathrm{M})$, respectively. To validate that NMDARs do not contribute to the zinc-mediated effects during the train, experiments in Fig. 2 and Fig. 3 were conducted in the presence of $50 \mu \mathrm{M}$ of NMDAR antagonist, DL-APV. ZX1 (100 $\mu \mathrm{M})$, AM-251 (1 $\mu \mathrm{M})$, WIN 55, 212-2 (50 nM), cyclothiazide $(100 \mu \mathrm{M})$, and kynurenic acid (0.5-1 mm) were always bath applied. All drugs were dissolved in deionized water, except for WIN $55,212-2$, which used DMSO as vehicle; the final concentration of DMSO was $<0.5 \%$. The experimenter was blinded to the genotype in experiments involving ZnT3WT and ZnT3KO mice. Once the experimenter completed the analysis of experiments from individual mice, he received 
A

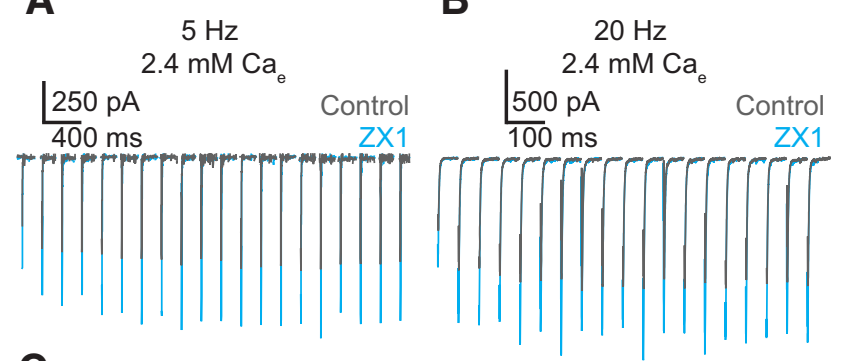

C

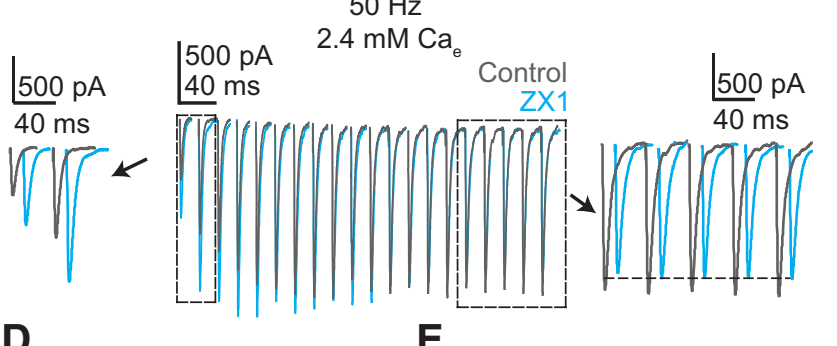

D

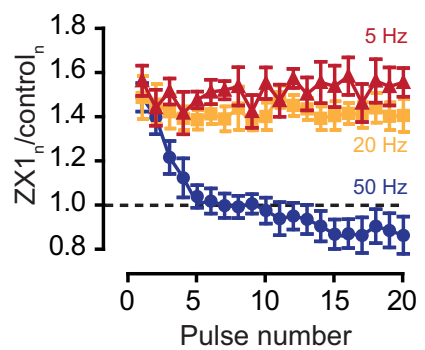

E

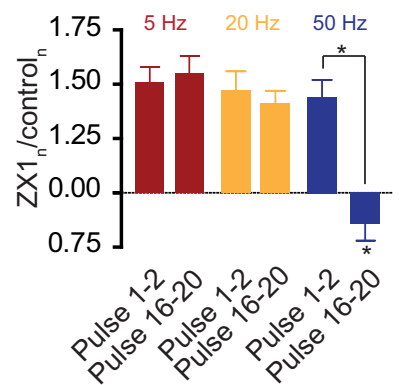

Figure 1. Frequency- and history-dependent effects of synaptically released zinc on AMPA EPSCs. $\boldsymbol{A}-\boldsymbol{C}$, Representative traces of cartwheel cell AMPA EPSCs evoked by 20-pulse train stimulation of parallel fiber at $5 \mathrm{~Hz}(\boldsymbol{A}), 20 \mathrm{~Hz}(\boldsymbol{B})$, and $50 \mathrm{~Hz}(\boldsymbol{C}$ middle panel), before (grey) and after $100 \mu \mathrm{M}$ ZX1 (blue); ( $\boldsymbol{C}$ side panels) same as in upper panel but zoomed on the first 2 pulses (left) and the last 5 pulses (right). For improved visualization, responses after ZX1 are slightly shifted to the right. $\boldsymbol{D}$, Summary graph showing the ratio of AMPA EPSCs in ZX1 to that in control at each pulse at $5 \mathrm{~Hz}$ (maroon), $20 \mathrm{~Hz}$ (orange), and $50 \mathrm{~Hz}$ (blue). $\boldsymbol{E}$, Summary graph comparing the ratio of AMPA EPSCs in ZX1 to that in control for the first two and last five pulses in the 20-pulse train at $5 \mathrm{~Hz}$ (maroon, $n=10, p=0.82$ ), $20 \mathrm{~Hz}$ (orange, $n=10$, $p=0.63$ ), and $50 \mathrm{~Hz}$ (blue, $n=10, p<0.01$ ). Values represent mean \pm SEM. Detailed values and statistical tests: $\boldsymbol{D}, \boldsymbol{E}, \mathrm{ZX}_{1-2} /$ control $_{1-2}$ vs. ZX IX-20 $_{16}$ control $_{16-20}: 5 \mathrm{~Hz}: 1.51 \pm 0.07$ vs. $1.55 \pm$ $0.08, n=10, p=0.82, t=0.24$, df $=9 ; 20 \mathrm{~Hz}: 1.47 \pm 0.09$ vs. $1.41 \pm 0.06, n=10, p=0.63, t=0.49$, df $=9 ; 50 \mathrm{~Hz}: 1.44 \pm$ 0.07 vs. $0.86 \pm 0.08, n=10, p<0.01, t=5.45, \mathrm{df}=9$; paired $t$-tests; ZX 1-2 $_{\text {/control }}$ :2: $5 \mathrm{~Hz}$ vs. $20 \mathrm{~Hz}, p=0.65, t=0.46$, df $=$ 9; $5 \mathrm{~Hz}$ vs. $50 \mathrm{~Hz}, p=0.38, t=0.92, \mathrm{df}=9 ; 20 \mathrm{~Hz}$ vs. $50 \mathrm{~Hz}$, $p=0.68, t=0.42, \mathrm{df}=9 ; \mathrm{ZX}_{16-20}$ /control $_{16-20:} 5 \mathrm{~Hz}$ vs. 20 $\mathrm{Hz}, p=0.09, t=1.87$, df $=9 ; 5 \mathrm{~Hz}$ vs. $50 \mathrm{~Hz}, p<0.01, t=$ $5.09, \mathrm{df}=9 ; 20 \mathrm{~Hz}$ vs $50 \mathrm{~Hz}, p<0.01, t=4.98$, df = 9; paired $t$-tests; AMPA EPSC amplitudes $16-20$ : control: $50 \mathrm{~Hz}: 1.00 \pm$ 0.00 vs. $Z X 1: 0.86 \pm 0.08, p=0.042, t=2.36, \mathrm{df}=9$; one-sample $t$-test.

information regarding the grouping of mice. After the experimenter averaged the data from the two groups of mice, he was informed on the genotype of the two groups.
A

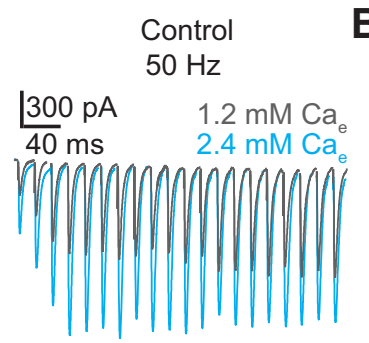

B ZX1
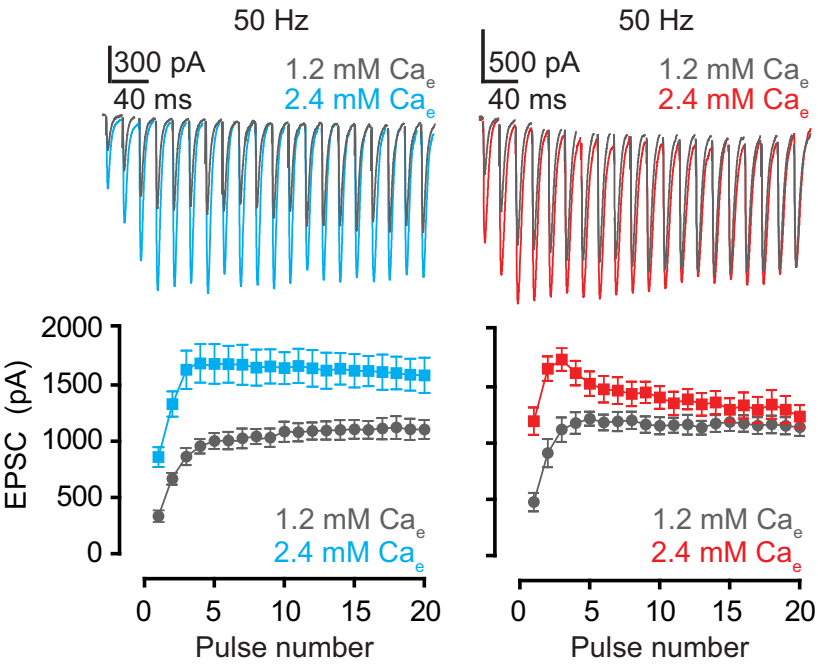

C

ZnT3 WT

ZnT3 KO

$50 \mathrm{~Hz}$
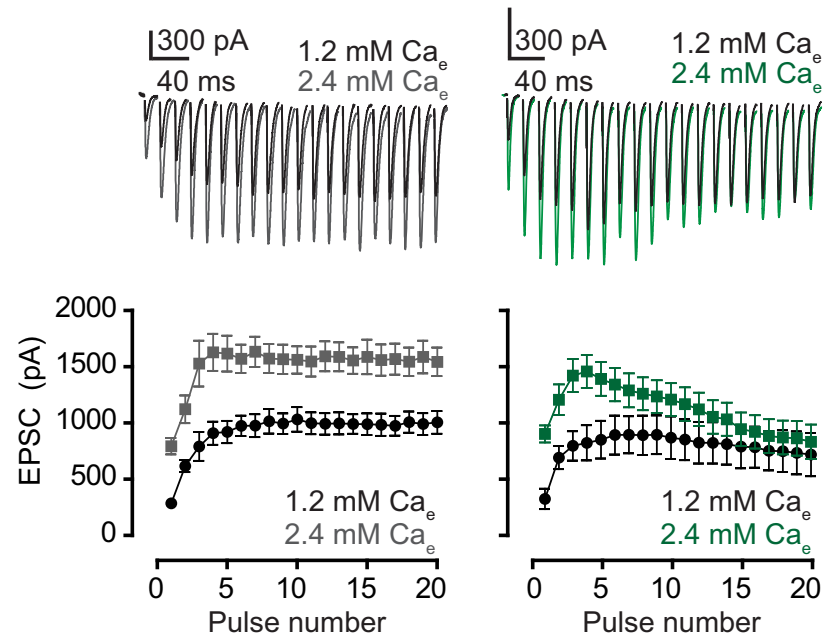

Figure 2. ZnT3-dependent, synaptically released zinc enhances EPSC $_{S S}$ in high Pr. $\boldsymbol{A}, \boldsymbol{B}$, Upper panels, representative traces of AMPA EPSCs evoked by $50-\mathrm{Hz} 20$-pulse train in $1.2 \mathrm{~mm}$ (gray) and $2.4 \mathrm{~mm}$ (color) external calcium in control $(\boldsymbol{A})$ and ZX1 $(\boldsymbol{B})$. Lower panels, summary graphs showing average AMPA EPSC amplitudes during the train in $1.2 \mathrm{~mm}$ (gray) and $2.4 \mathrm{~mm}$ (color) external calcium in control $(\boldsymbol{A})$ and $Z \mathbf{X} 1$ (B; EPSC $_{16-20}$ amplitude: control: 1.2 vs. $2.4 \mathrm{~mm}: n=7, p<0.01$; ZX1: 1.2 vs. $2.4 \mathrm{~mm}: n=$ $7, p=0.09$ ). $\boldsymbol{C}, \boldsymbol{D}$, Upper panels, representative traces of AMPA EPSCs evoked by $50-\mathrm{Hz} 20$-pulse train in $1.2 \mathrm{~mm}$ (black) and 2.4 mм (gray or green) external calcium in ZnT3WT (C) and ZnT3KO mice $(\boldsymbol{D})$. Lower panels, summary graphs showing average AMPA EPSC amplitudes during the train in $1.2 \mathrm{~mm}$ (black) and $2.4 \mathrm{~mm}$ (gray or green) external calcium in ZnT3WT (C) and ZnT3KO mice ( $\boldsymbol{D}$; ZnT3 WT: 1.2 vs. 2.4 mм: $n=5, p<0.01$; ZnT3KO: 1.2 vs. $2.4 \mathrm{~mm}: n=5, p=0.24)$. Values represent mean \pm SEM.

Detailed values and statistical tests. $\boldsymbol{A}, \boldsymbol{B}$, lower panels: EPSC $_{16-20}$ amplitude: control: $1.2 \mathrm{~mm}$ calcium: $1109 \mathrm{pA} \pm 90 \mathrm{pA}$ vs. $2.4 \mathrm{~mm}$ calcium: $1605 \mathrm{pA} \pm 147 \mathrm{pA}, n=7, p<0.01, F=$ 40.89, DFn = 1, DFd = 60; ZX1: $1.2 \mathrm{~mm}$ calcium: $1158 \mathrm{pA} \pm 75$ pA vs. $2.4 \mathrm{~mm}$ calcium: $1301 \mathrm{pA} \pm 116 \mathrm{pA}, n=7, p=0.09, F=$ 2.9, $\mathrm{DFn}=1$, DFd = 60; two-way ANOVA. $\boldsymbol{C}, \boldsymbol{D}$, lower panels: 
continued

EPSC $_{16-20}$ amplitude. ZnT3WT: $1.2 \mathrm{~mm}$ calcium: $996 \mathrm{pA} \pm 95 \mathrm{pA}$ vs. $2.4 \mathrm{~mm}$ calcium: $1564 \mathrm{pA} \pm 135 \mathrm{pA}, n=5, p<0.01, F=$ 58.51, DFn = 1, DFd = 40; ZnT3KO: $1.2 \mathrm{~mm}$ calcium: $750 \mathrm{pA} \pm$ $185 \mathrm{pA}$ vs. $2.4 \mathrm{~mm}$ calcium: $876 \mathrm{pA} \pm 156 \mathrm{pA}, n=5, p=0.24$, $F=1.40$, DFn $=1$, DFd $=40$; two-way ANOVA.

\section{Drugs}

SR95531, DL-APV, and strychnine were purchased from Hello-Bio. AM-251, WIN 55, 212-2, QX-314, cyclothiazide, and kynurenic acid were purchased from Tocris. ZX1 was purchased from STREM Chemicals.

\section{Statistics}

For statistical comparisons, paired $t$ tests and unpaired $t$ tests were used if the group data passed the Lilliefors test for normality. If the group data were not normally distributed, then the Wilcoxon rank sum test was used. For normalized data, one-sample $t$-test was used. We used two-way ANOVA for comparisons of data groups
A AM-251
$50 \mathrm{~Hz}$ in $2.4 \mathrm{mM} \mathrm{Ca}_{\mathrm{e}}$

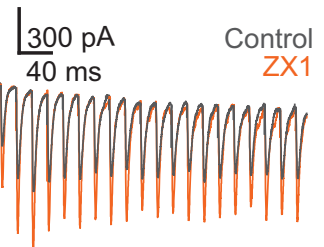
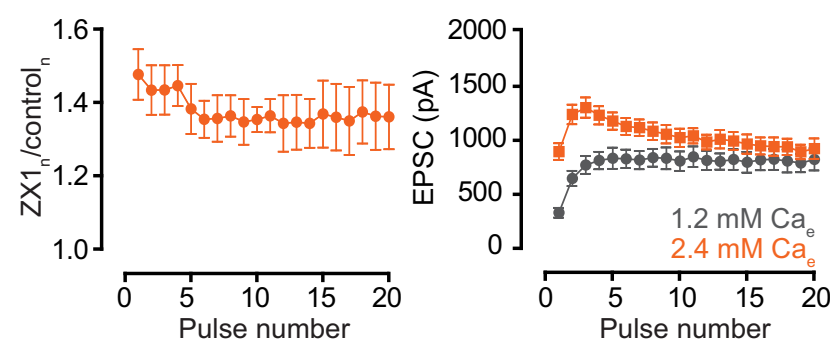

Figure 3. Endocannabinoid signaling is necessary for the zincmediated enhancement of $\mathrm{EPSC}_{\mathrm{Ss}}$. $\boldsymbol{A}$, Upper panel, representative traces of AMPA EPSCs, evoked by $50-\mathrm{Hz} 20$-pulse train, in the presence of $1 \mu \mathrm{M}$ AM-251 before (gray) and after ZX1 (orange). Lower panel, summary graph showing average ratios of AMPA EPSCs in the presence of $Z X 1$ to that in control during the train $\left(Z_{1-2}\right.$ control $_{1-2}$ vs. $Z_{16-20}$ control $_{16-20}: 50 \mathrm{~Hz}: n=5, p=$ 0.13). $\boldsymbol{B}$, Upper panel, representative traces of AMPA EPSCs evoked by $50-\mathrm{Hz} 20$-pulse train in $1.2 \mathrm{~mm}$ (gray) and $2.4 \mathrm{~mm}$ (orange) external calcium in the presence of AM-251. Lower panel, summary graph showing average AMPA EPSC amplitudes during the train in $1.2 \mathrm{~mm}$ (gray) and $2.4 \mathrm{~mm}$ (orange) external calcium in the presence of AM-251. (EPSC $_{16-20}$ amplitude in AM-251: 1.2 vs. $2.4 \mathrm{~mm}$ calcium, $n=5, p=0$. 09). Values represent mean \pm SEM.

Detailed values and statistical tests: $\boldsymbol{A}$, lower panel: $Z_{X_{1-2}} /$ control $_{1-2}$ vs. $Z_{16-20}$ /control $_{16-20}: 50 \mathrm{~Hz}$ : control: $1.47 \pm 0.06$ vs. ZX1: $1.36 \pm 0.08, n=5, p=0.13, t=1.4$, df $=9$; paired $t$-test. B, lower panel: EPSC ${ }_{16-20}$ amplitude: AM-251: $1.2 \mathrm{mM}$ calcium: $805 \mathrm{pA} \pm 97 \mathrm{pA}$ vs. $2.4 \mathrm{~mm}$ calcium: $921 \mathrm{pA} \pm 80 \mathrm{pA}, n=5, p$ $=0.19, F=1.7$, DFn $=1$, DFd $=40$; two-way ANOVA. including multiple $\mathrm{Ca}$ levels shown in Figs. 2, 3B, $4 B, 4 D$, $5 A, 5 B, 6 A, 6 G$, and $7 B$.

\section{Results}

\section{Synaptically released zinc enhances steady-state AMPA EPSC during high Pr and high-frequency trains}

To investigate the impact of synaptically released zinc in neurotransmission during different frequencies and levels of synaptic activity, we studied zinc-mediated neuromodulation in cartwheel cells. Cartwheel cells represent a class of inhibitory interneurons located in the molecular layer of the DCN, a cerebellar-like structure in the auditory brainstem (Oertel and Young, 2004). Cartwheel cells receive glutamatergic input from zinc-rich parallel fibers (PFs; Frederickson et al., 1988). In response to PF stimulation by a 20 -pulse train at 5 or $20 \mathrm{~Hz}$, zinc chelation with the extracellular, high-affinity, fast chelator, ZX1 (Pan et al., 2011; Anderson et al., 2015), potentiated AMPA EPSC amplitudes (Fig. 1A, B). Moreover, the amount of this increase was constant throughout the stimulus train (Fig. $1 A, B, D, E$ ). This result suggests that the effect of zinc is a steady subtractive inhibition of AMPA EPSC, readily predicted by the postsynaptic inhibitory effect of zinc on AMPARs in response to a single stimulus (Kalappa et al., 2015). In contrast to these findings, during the 20-pulse stimulation at $50 \mathrm{~Hz}$, ZX1 enhanced AMPA EPSC in the first two to four pulses but, paradoxically, inhibited steady-state responses $\left(\mathrm{EPSC}_{\mathrm{SS}}\right)$ during the last four pulses (Fig. 1C-E). This result suggests that the modulatory effects of zinc depend on the history of the synapse: during high-frequency stimulation, zinc inhibits EPSCs for the first few stimuli, but later in the stimulus train, it enhances EPSC $_{S S}$. Given the known inhibitory role of zinc on synaptic strength, the zinc-mediated enhancement of EPSC $\mathrm{SS}_{\mathrm{S}}$ was unexpected.

The zinc-dependent enhancing effect on $\mathrm{EPSC}_{\mathrm{SS}}$ was observed during high-frequency stimulation, which is associated with increases in Pr. To further interrogate the influence of $\mathrm{Pr}$ on $\mathrm{EPSC}_{\mathrm{SS}}$ amplitudes, we manipulated $\mathrm{Pr}$ by using different extracellular calcium concentrations $\left(\mathrm{Ca}_{\mathrm{e}}\right)$. Within the same cell, increasing $\mathrm{Ca}_{\mathrm{e}}$ from $1.2 \mathrm{~mm}$ (low $\mathrm{Pr}$ ) to $2.4 \mathrm{~mm}$ (high $\mathrm{Pr}$ ) resulted in an increase in EPSC $_{\text {SS }}$ amplitude (Fig. 2A). Previous studies on the homologous cerebellar PF synapses onto Purkinje neurons, which lack synaptic zinc, showed that alterations in $\mathrm{Pr}$ do not affect $\mathrm{EPSC}_{\mathrm{SS}}$ amplitudes during $50-\mathrm{Hz}$ trains (Kreitzer and Regehr, 2000). Because zinc enhances AMPA EPSC $_{S S}$ in DCN synapses during high-frequency trains (Fig. $1 C, E$ ), we hypothesized that zinc signaling is necessary for the increase in steady-state responses in higher $\mathrm{Ca}_{\mathrm{e}}$. To test this hypothesis, we conducted similar experiments as in Fig. $2 A$ but in the presence of $Z X 1$. In these experiments, stimulation of PFs using the same 20-pulse $50-\mathrm{Hz}$ train resulted in AMPAR EPSC ${ }_{\mathrm{SS}}$ amplitudes that were not different between high and low Pr conditions (Fig. 2B). These results suggest that during highfrequency stimulation, endogenous zinc enhances EP$\mathrm{SC}_{\mathrm{SS}}$ in higher $\mathrm{Pr}$. 
To determine whether synaptically released zinc was required for the enhanced $\mathrm{EPSC}_{\mathrm{SS}}$ during high-frequency stimulation, we investigated EPSCss in PF to cartwheel cell synapses from mice lacking the ZnT3 transporter (ZnT3KO mice), which lack synaptically released zinc throughout the brain (Cole et al., 1999). In ZnT3KO mice, EPSC $_{\text {SS }}$ evoked by a 20-pulse train stimulus at $50 \mathrm{~Hz}$ did not differ between 1.2 and $2.4 \mathrm{~mm} \mathrm{Ca}_{\mathrm{e}}$ (Fig. 2D), but EPSC $_{S S}$ in ZnT3WT mice were larger in $2.4 \mathrm{~mm} \mathrm{Ca}_{\mathrm{e}}$ (Fig. $2 C)$. Given that tonic zinc levels in the DCN are ZnT3 independent (Anderson et al., 2015), these results suggest that ZnT3-dependent synaptically released zinc enhances EPSC $_{S S}$ in high Pr.

\section{Synaptic zinc-mediated endocannabinoid signaling enhances steady-state AMPAR EPSC by enhancing synaptic facilitation}

Zinc triggers endocannabinoid release after trains of presynaptic action potentials (Perez-Rosello et al., 2013). We therefore tested whether endocannabinoid signaling is necessary for the zinc-dependent enhancement of EPSC $_{S S}$. In the presence of $1 \mu \mathrm{M}$ AM-251, a cannabinoid receptor 1 specific antagonist (Lan et al., 1999), we did not observe any change in the amount of ZX1 potentiation throughout the $50-\mathrm{Hz}$ stimulation (Fig. $3 A$ ). Moreover, in ZX1, EPSC ${ }_{\mathrm{SS}}$ were not different between 1.2 and $2.4 \mathrm{~mm}$ $\mathrm{Ca}_{\mathrm{e}}$ (Fig. $3 B$ ). These results suggest that endocannabinoid signaling is necessary for the zinc-dependent enhancement of EPSC SS. $_{\text {. }}$

By reducing $\operatorname{Pr}$ (Kreitzer and Regehr, 2002; Wilson and Nicoll, 2002), endocannabinoid signaling may also reduce the effect of postsynaptic factors that inhibit EPSC $_{S S}$, such as receptor saturation and desensitization (Trussell et al., 1993; Wadiche and Jahr, 2001; Chen et al., 2002; Foster et al., 2002). Alternatively, endocannabinoid signaling may enhance presynaptic factors that also enhance EPSC $_{\text {SS }}$, such as synaptic facilitation (Zucker and Regehr, 2002).

First we investigated whether reductions in AMPAR saturation or desensitization contribute to enhanced

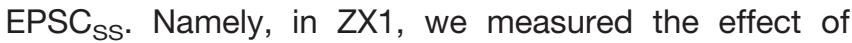
kynurenic acid $(0.5-1 \mathrm{~mm})$ or cyclothiazide $(100 \mu \mathrm{M})$ in $\mathrm{EPSC}_{\mathrm{SS}}$, with either 1.2 or $2.4 \mathrm{~mm} \mathrm{Ca}$. Kynurenic acid is a competitive AMPAR antagonist (Fig. $4 A$ ) that inhibits receptor saturation, and cyclothiazide is an allosteric modulator (Fig. 4C) that inhibits AMPAR desensitization (Partin et al., 1994, 1996; Neher and Sakaba, 2001; Prescott et al., 2006). If the enhancing effect of zinc on EPSC $_{S S}$ was mediated by a zinc-driven decrease in AMPAR saturation or desensitization, blockade of these processes would enhance EPSC $_{S S}$ in high Pr even in the presence of ZX1. Under these conditions, high Pr did not enhance $\mathrm{EPSC}_{\mathrm{SS}}$ (Fig. 4B, D), suggesting that the enhancing effect of zinc on EPSC $_{S S}$ is not due to either AMPAR saturation or desensitization.

Next we investigated whether endogenous zinc enhances EPSC $_{S S}$ by endocannabinoid-mediated Pr reduction and a subsequent enhancement of synaptic facilitation. Consistent with this hypothesis, ZX1 decreased AMPA EPSC facilitation at $50 \mathrm{~Hz}$ (Fig. 5A). In
A

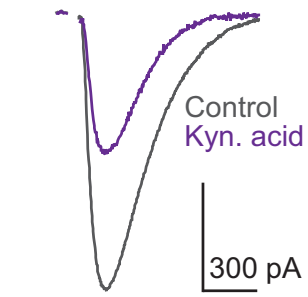

B

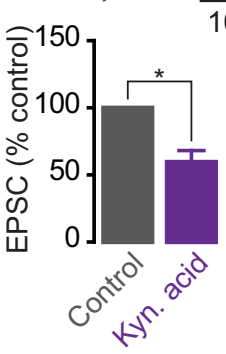

C
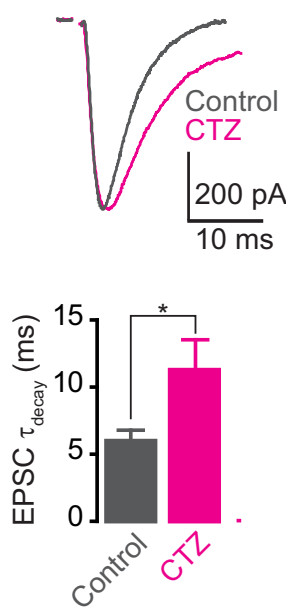

D
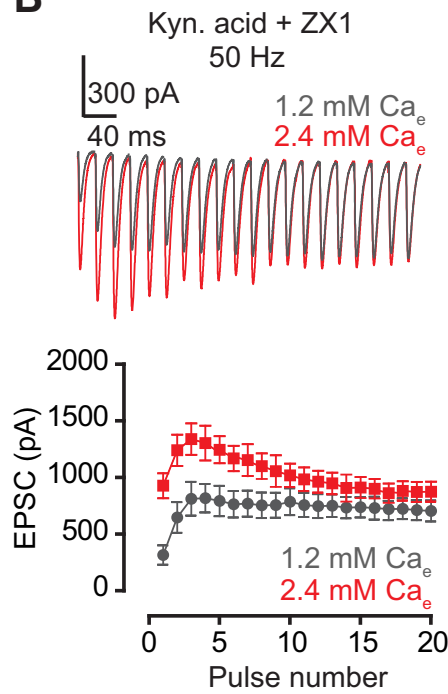

$\mathrm{CTZ}+\mathrm{ZX} 1$

$50 \mathrm{~Hz}$
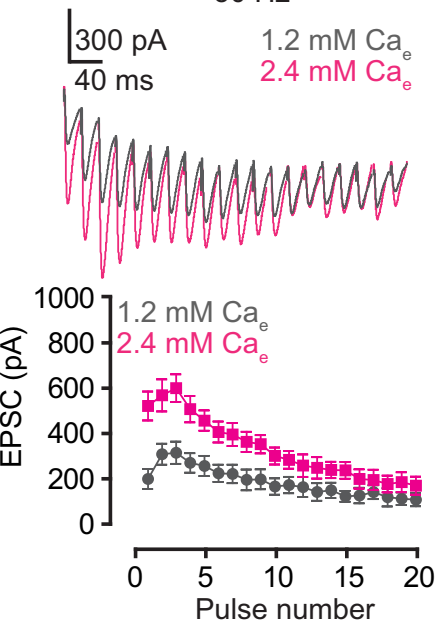

Figure 4. AMPAR saturation or desensitization do not contribute to the zinc-mediated enhancement of EPSC $_{S S}$. A, C, Upper panels, representative traces of AMPA EPSCs before (gray) and after (color) bath application of 0.5-1 mm kynurenic acid $(\boldsymbol{A})$ and $100 \mu \mathrm{m}$ cyclothiazide (C). Lower panels, summary graphs showing normalized AMPA EPSC amplitude $(\boldsymbol{A})$ and decay time constant $(\boldsymbol{C})$, before (gray) and after (color) $0.5-1$ mm kynurenic acid (A) and $100 \mu \mathrm{M}$ cyclothiazide (C; AMPA EPSC amplitude: control vs. kynurenic acid, $n=5, p<0.01$; AMPA EPSC decay time constant: control vs. cyclothiazide, $n=5, p=0.04)$. $\boldsymbol{B}, \boldsymbol{D}$, Upper panels, representative traces of AMPA EPSCs evoked by $50-\mathrm{Hz}$ 20-pulse train in $1.2 \mathrm{~mm}$ (gray) and $2.4 \mathrm{~mm}$ (color) external calcium, in 0.5-1 mm kynurenic acid and ZX1 (B) or in $100 \mu \mathrm{M}$ cyclothiazide and ZX1 (D). Lower panels, summary graphs showing average AMPA EPSC amplitudes during the train, in kynurenic acid and ZX1 $(\boldsymbol{B})$, or in cyclothiazide and ZX1 (D). (EPSC $_{16-20}$ amplitude: kynurenic acid: 1.2 vs. 2.4 mm calcium, $n$ $=5, p=0.13$; cyclothiazide: 1.2 vs. $2.4 \mathrm{~mm}$ calcium, $n=5, p=$ 0.06 .) Values represent mean \pm SEM.

Detailed values and statistical tests: $\boldsymbol{A}$, lower panel: AMPA EPSC amplitude in the presence of kynurenic acid: $59.63 \% \pm 8.5 \%$ of baseline, $n=5, p<0.01, t=4.74$, df $=4$; one-sample $t$-test. $\boldsymbol{C}$, lower panel: AMPA EPSC decay time constant: control vs. cyclothiazide: $5.99 \pm 0.81$ vs. $11.32 \pm 2.15, n=5, p=0.04$; paired 
continued

$t$-test, $t=2.95$, df $=4$. $B$, lower panel: EPSC $_{16-20}$ amplitude: kynurenic acid: $1.2 \mathrm{~mm}$ calcium: $718 \mathrm{pA} \pm 94 \mathrm{pA}$ vs. $2.4 \mathrm{~mm}$ calcium: $812 \mathrm{pA} \pm 96 \mathrm{pA}, n=5, p=0.13, F=2.37$, DFn $=1$, $\mathrm{DFd}=40$; two-way ANOVA. $\boldsymbol{D}$, lower panel: cyclothiazide: 1.2 mM calcium: $122 \mathrm{pA} \pm 32 \mathrm{pA}$ vs. $2.4 \mathrm{~mm}$ calcium: $186 \mathrm{pA} \pm 41$ $\mathrm{pA}, n=5, p=0.06, F=3.6$, DFn $=1$, DFd $=40$; two-way ANOVA.

contrast, in the presence of AM-251, ZX1 did not decrease AMPA EPSC facilitation (Fig. 5B), suggesting that endocannabinoid signaling and enhanced synaptic facilitation are necessary for the zinc-mediated augmentation of EPSC Ss. $_{\text {. }}$

Consistent with the lack of effect of ZX1 in enhancing $E_{\text {EPSC }}$ at lower stimulation frequencies (Fig. 1A, B, D, E), ZX1 did not affect synaptic facilitation at these frequencies in either 1.2 or $2.4 \mathrm{~mm} \mathrm{Ca}_{\mathrm{e}}$ (Fig. $6 A-D$ ). In contrast, ZX1 decreased synaptic facilitation at $50 \mathrm{~Hz}$ in $1.2 \mathrm{~mm}$ $\mathrm{Ca}_{\mathrm{e}}$. However, ZX1 decreased synaptic facilitation by the eighth pulse in $1.2 \mathrm{~mm} \mathrm{Ca}_{\mathrm{e}}$, but in $2.4 \mathrm{mM} \mathrm{Ca}_{\mathrm{e}}$ it decreased facilitation by the third pulse (Fig. $5 A$ vs. Fig. $6 E$ ). This
A

$50 \mathrm{~Hz}$ in $2.4 \mathrm{mM} \mathrm{Ca}$
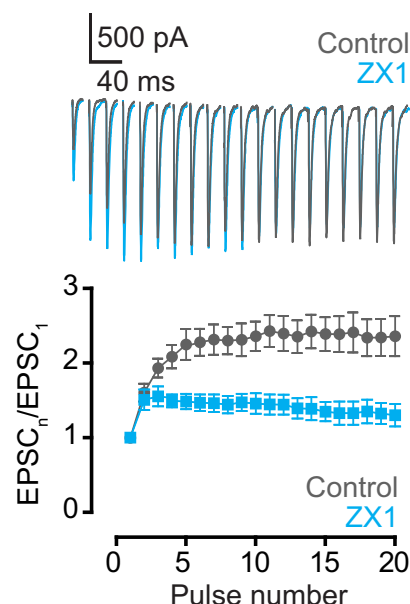

\section{B}

AM-251 $50 \mathrm{~Hz}$ in $2.4 \mathrm{mM} \mathrm{Ca}$ $300 \mathrm{pA} \quad$ Control $40 \mathrm{~ms} \quad \mathrm{ZX1}$
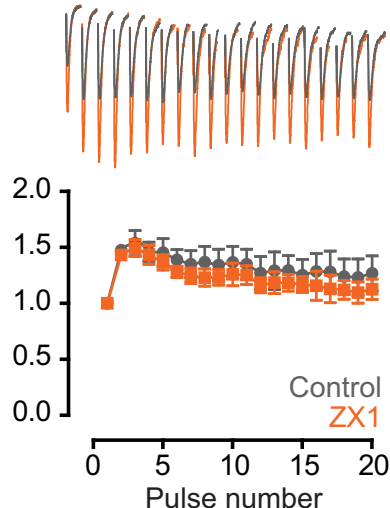

Figure 5. Enhanced zinc-mediated synaptic facilitation depends on endocannabinoid signaling. $\boldsymbol{A}, \boldsymbol{B}$, Upper panels, representative traces of AMPA EPSCs evoked by $50-\mathrm{Hz} 20$-pulse train before (gray) and after ZX1 application (color), in the absence $(\boldsymbol{A})$ or presence $(\boldsymbol{B})$ of $\mathrm{AM}-251$. Lower panels, summary graphs showing average AMPA EPSC amplitudes during the train, normalized to EPSC amplitude elicited by first pulse, before ( $\boldsymbol{A}$ and $\boldsymbol{B}$, gray) and after ( $\boldsymbol{A}$ and $\boldsymbol{B}$, color) ZX1 application, in the absence $(\boldsymbol{A})$, or presence $(\boldsymbol{B})$ of AM-251 (ratio of the amplitude of 16-20 EPSC to first EPSC at $50 \mathrm{~Hz}$ : in the absence of AM-251: control vs. ZX1, $n=10, p<0.01$; in the presence of AM-251: control vs. ZX1, $n=5, p=0.32$ ). Values represent mean $\pm \mathrm{SEM}$. Detailed values and statistical tests: Lower panels: ratio of the amplitude of 16-20 EPSC to first EPSC at $50 \mathrm{~Hz}$ : in the absence of AM-251: control: $2.29 \pm 0.25$ vs. ZX1: $1.32 \pm 0.15, n=10, p$ $<0.01, F=52.81$, DFn $=1$, DFd $=90$; in the presence of AM-251: control: $1.19 \pm 0.15$ vs. ZX1: $1.04 \pm 0.09, n=5, p=$ $0.32, F=1.0, \mathrm{DFn}=1$, DFd $=40$; two-way ANOVA. result is consistent with the more robust zinc-dependent endocannabinoid signaling occurring at higher $\mathrm{Pr}$, which is reflected by the requirement for fewer stimuli to elicit endocannabinoid release in higher $\mathrm{Pr}$ (Perez-Rosello et al., 2013). Finally, ZX1 did not change synaptic facilitation at $50 \mathrm{~Hz}$ in ZnT3KO mice (Fig. 6F-H). Together, these results suggest that synaptically released zinc results in increased synaptic facilitation and enhanced $\mathrm{EPSC}_{\mathrm{SS}}$, via retrograde endocannabinoid signaling and decreased $\mathrm{Pr}$.

Elimination of the postsynaptic inhibitory effect of zinc on AMPA EPSC amplitude during the $50-\mathrm{Hz}$ train could also contribute to the zinc-mediated enhancement of synaptic facilitation. To explore this possibility, we occluded the endocannabinoid-mediated effect on synaptic facilitation by applying 50 nM WIN 55, 212-2 (WIN), a CB1 receptor activator. Then, we tested whether this occlusion affected the ZX1 potentiation of the EPSC throughout the train. If a potential reduction of the postsynaptic inhibitory effect of zinc on AMPA EPSC amplitude during the $50-\mathrm{Hz}$ train was contributing to the zinc-mediated enhancement of synaptic facilitation, then occlusion of synaptic facilitation with WIN would also show a gradual reduction in the ZX1 potentiation throughout the train, as in Fig. 1D. We found that WIN occluded the effect of ZX1 on synaptic facilitation (Fig. $7 A, B$ ), and there was no reduction in the amount of ZX1 potentiation throughout the $50-\mathrm{Hz}$ train (Fig. 7A, C). This result suggests that changes in the magnitude of the postsynaptic inhibitory effect of zinc on AMPA EPSC do not contribute to the zinc-mediated enhancement of synaptic facilitation.

\section{Discussion}

Our results indicate that the effects of synaptically released zinc on excitatory neurotransmission are not purely inhibitory as previously thought, for zinc's actions depend on the level of activity of the target synapses. For synapses that are active at high rates of presynaptic activity, synaptically released zinc leads to an initial inhibition of postsynaptic activity, likely via direct inhibition of AMPARs (Kalappa et al., 2015), followed by the recruitment of endocannabinoid signaling that leads to reduced Pr but enhanced steady-state EPSCs. This seemingly paradoxical effect is likely explained by the fact that increased $\operatorname{Pr}$ depletes presynaptic vesicles, saturates release, and limits the extent of facilitation (Zucker and Regehr, 2002; Jackman et al., 2016). Whereas our findings are consistent with this hypothesis, we cannot rule out potential effects of presynaptic endocannabinoid signaling on the presynaptic calcium signal that induces facilitation or on the calcium sensor synaptotagmin 7 , which is required for synaptic facilitation (Jackman et al., 2016).

Facilitating synapses favor the transmission of burstlike presynaptic stimuli (Lisman, 1997; Abbott and Regehr, 2004). Whereas in vivo recordings from DCN granule cells have not been obtained, sensory stimulation produces bursts of high-frequency $(>200 \mathrm{~Hz}$ ) spikes in cerebellar granule cells (Chadderton et al., 2004). Although these bursts are briefer than the trains we used here, they also occur at higher frequencies. Based on our results 
A

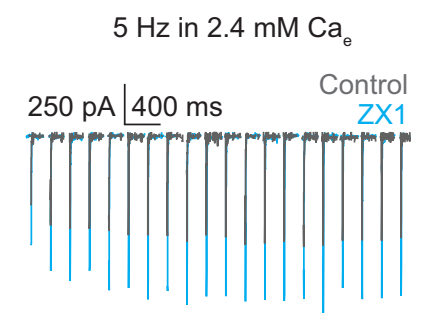

B $20 \mathrm{~Hz}$ in $2.4 \mathrm{mM} \mathrm{Ca}_{\mathrm{e}}$
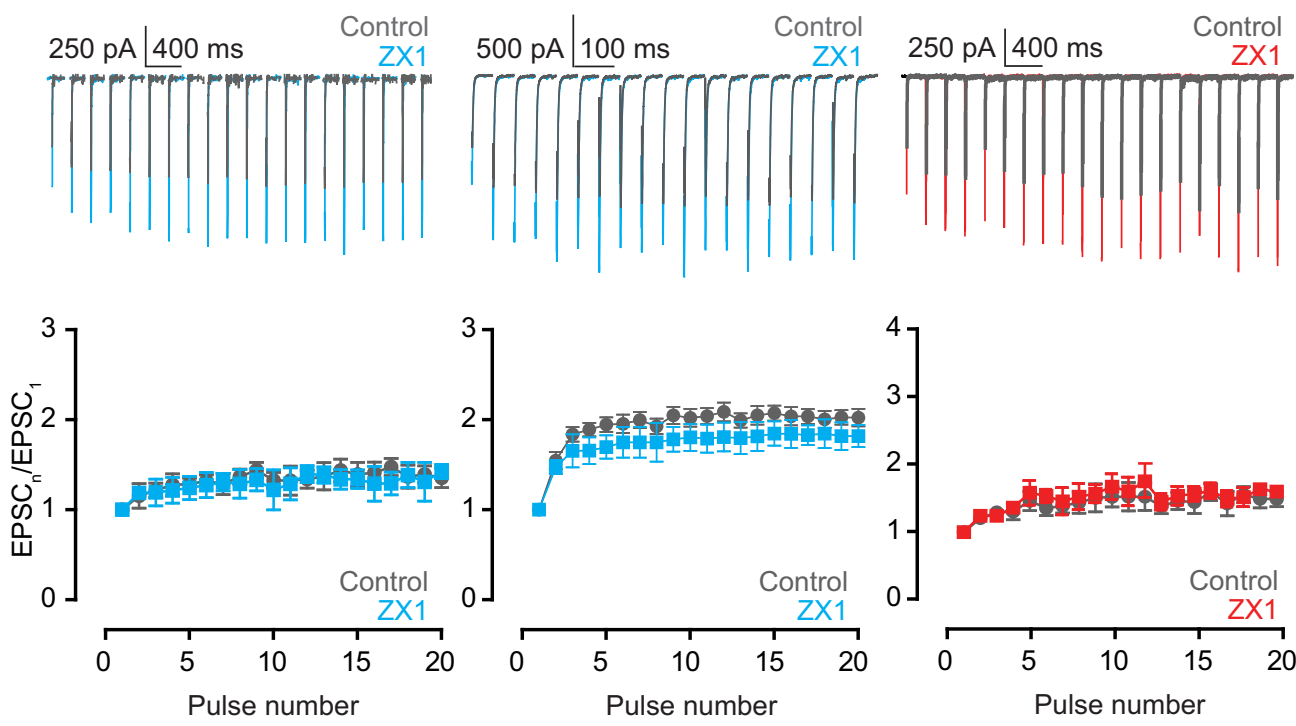

G

ZnT3 WT

$50 \mathrm{~Hz}$ in $1.2 \mathrm{mM} \mathrm{Ca}$

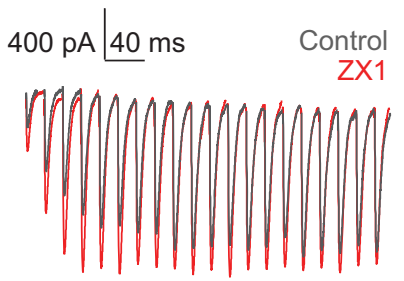

$50 \mathrm{~Hz}$ in $1.2 \mathrm{mM} \mathrm{Ca}$

C

$5 \mathrm{~Hz}$ in $1.2 \mathrm{mM} \mathrm{Ca}$
ZnT3 KO

$50 \mathrm{~Hz}$ in $1.2 \mathrm{mM} \mathrm{Ca}$
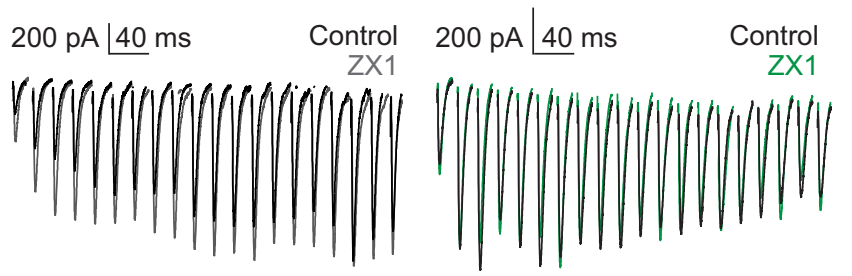

D

$20 \mathrm{~Hz}$ in $1.2 \mathrm{mM} \mathrm{Ca}_{\mathrm{e}}$
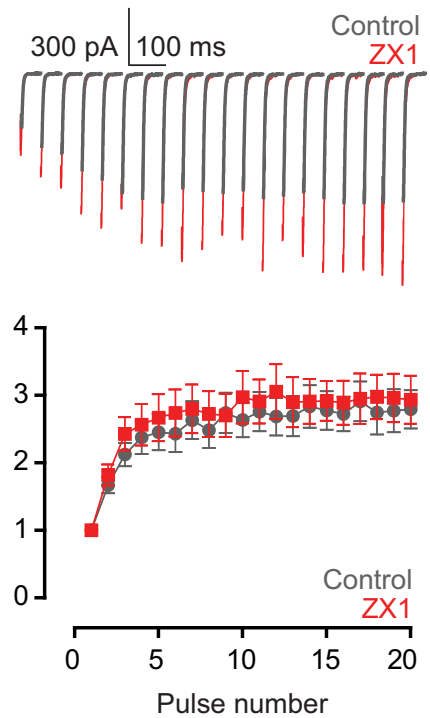

H

ZnT3 WT vs. ZnT3 KO $50 \mathrm{~Hz}$ in $1.2 \mathrm{mM} \mathrm{Ca}$
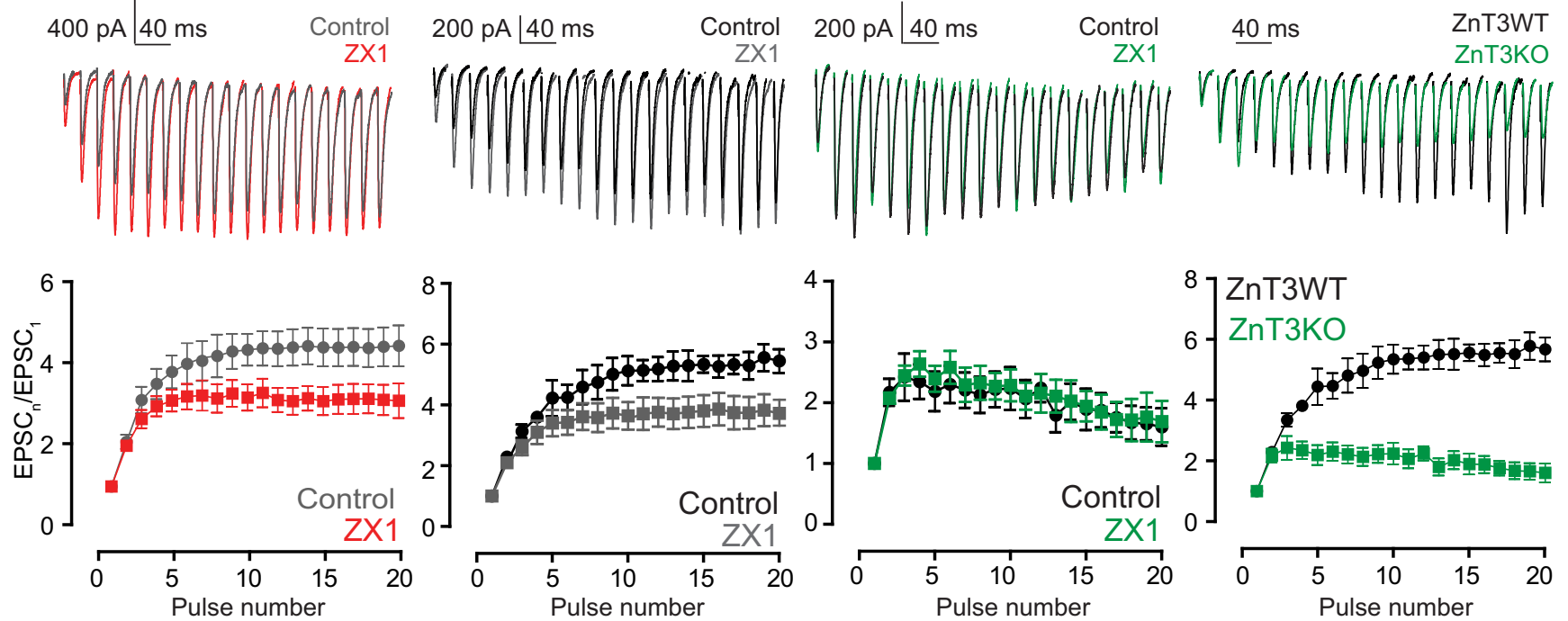

Figure 6. AMPA EPSC facilitation by synaptically released zinc is frequency, history, and $\operatorname{Pr}$ dependent. $\boldsymbol{A}$, $\boldsymbol{B}$, Upper panels, representative traces of AMPA EPSCs evoked by 20-pulse train at $5 \mathrm{~Hz}(\boldsymbol{A})$ and $20 \mathrm{~Hz}(\boldsymbol{B})$, before (gray) and after (color) $100 \mu \mathrm{M}$ ZX1, in $2.4 \mathrm{~mm}$ external calcium. Lower panels, summary graphs showing average AMPA EPSC amplitudes during the 20-pulse train, normalized to EPSC amplitude of the first pulse, before (gray) and after (color) ZX1 application at $5 \mathrm{~Hz}(\boldsymbol{A})$ and $20 \mathrm{~Hz}(\boldsymbol{B})$, in $2.4 \mathrm{~mm}$ external calcium (ratio of the amplitude of 16-20 EPSC to first EPSC: $2.4 \mathrm{~mm}$ calcium: $5 \mathrm{~Hz}$ : control vs. ZX1, $n=5, p=0.58 ; 20 \mathrm{~Hz}$ : control vs. ZX1, $n=5, p=0.09$ ). $\boldsymbol{C}-\boldsymbol{E}$, Upper panels, representative traces of AMPA EPSCs evoked by 20-pulse train at $5 \mathrm{~Hz}(\boldsymbol{C})$, $20 \mathrm{~Hz}(\boldsymbol{D})$, and $50 \mathrm{~Hz}(\boldsymbol{E})$, before (gray) and after (color) $100 \mu \mathrm{M} Z \mathrm{ZX1}$, in $1.2 \mathrm{~mm}$ external calcium. Lower panels, summary graphs showing average AMPA EPSC amplitudes during the 20-pulse train, normalized to EPSC amplitude of the first pulse, before (gray) and after (color) ZX1 application at $5 \mathrm{~Hz}(\boldsymbol{C}), 20 \mathrm{~Hz}(\boldsymbol{D})$, and $50 \mathrm{~Hz}(\boldsymbol{E})$ in $1.2 \mathrm{~mm}$ external calcium (ratio of the amplitude of 16-20 EPSC to first EPSC: $1.2 \mathrm{~mm}$ calcium: $5 \mathrm{~Hz}$ : control vs. ZX1, $n=5, p=0.34 ; 20 \mathrm{~Hz}$ : control vs. ZX1, $n=5, p=0.45 ; 50 \mathrm{~Hz}$ vs. ZX1, $n=$ $10, p<0.01) . F, G$, Upper panels, representative traces of AMPA EPSCs evoked by $50-\mathrm{Hz} 20$-pulse train, before (black) and after (color) $100 \mu \mathrm{M} Z \mathbf{Z X 1}$, in ZnT3WT $(\boldsymbol{F})$ and ZnT3KO $(\boldsymbol{G})$ mice. Lower panels, summary graphs showing average AMPA EPSC amplitudes during the 50-Hz 20-pulse train, normalized to EPSC amplitude of the first pulse, before (black) and after (color) ZX1 application, in ZnT3WT $(\boldsymbol{F})$ and ZnT3KO (G) mice (ratio of the amplitude of 16-20 EPSC to first EPSC: ZnT3WT mice: $50 \mathrm{~Hz}$ control vs. ZX1, $n=6$, $p<0.01$; ZnT3KO mice: $50 \mathrm{~Hz}$ : control vs. ZX1, $n=5, p=0.85)$. $\boldsymbol{H}$, Upper panel, representative traces of peak-scaled AMPA EPSCs evoked by 50-Hz 20-pulse train in ZnT3WT (black) and ZnT3KO mice (green). Lower panel, summary graphs showing average AMPA 
continued

EPSC amplitudes during the $50-\mathrm{Hz} 20$ pulse train, normalized to EPSC amplitude of the first pulse in control conditions, in ZnT3WT (black) and ZnT3KO (color) mice (ratio of the amplitude of 20 EPSC to first EPSC: ZnT3WT vs. ZnT3KO: control: $50 \mathrm{~Hz}, n=5, p<$ 0.01). Values represent mean \pm SEM.

Detailed values and statistical tests: $\boldsymbol{A}, \boldsymbol{B}$, lower panels: ratio of the amplitude of 16-20 EPSC to first EPSC: $2.4 \mathrm{~mm}$ calcium: $5 \mathrm{~Hz}$ : control: $1.40 \pm 0.12$ vs. ZX1: $1.34 \pm 0.15, n=5, p=0.58, F=0.31$, DFn =1, DFd = 40; 20 Hz: control: $2.03 \pm 0.09$ vs. ZX1: 1.83 $\pm 0.14, n=5, p=0.09, F=3.0, \mathrm{DFn}=1$, DFd $=40$; two-way ANOVA. $\boldsymbol{C}-\boldsymbol{E}$, lower panels: ratio of the amplitude of $16-20$ EPSC to first EPSC: $1.2 \mathrm{~mm}$ calcium: $5 \mathrm{~Hz}$ : control: $1.54 \pm 0.14 \mathrm{vs}$. ZX1: $1.61 \pm 0.11, n=5, p=0.34, F=0.9$, DFn $=1$, DFd $=40 ; 20 \mathrm{~Hz}$ : control: $2.78 \pm 0.29$ vs. ZX1: $2.94 \pm 0.34, n=5, p=0.45, F=0.56$, DFn $=1$, DFd = 40; $50 \mathrm{~Hz}: 4.44 \pm 0.47$ vs. ZX1: $3.14 \pm 0.37$, $n=10, p<0.01, F=22.59$, DFn $=1$, DFd $=90$; two-way ANOVA. $\boldsymbol{F}, \boldsymbol{G}$, lower panels: ratio of the amplitude of $16-20 \mathrm{EPSC}$ to first EPSC: ZnT3WT mice: $50 \mathrm{~Hz}: 5.580 \pm 0.39$ vs. ZX1: $3.96 \pm 0.55, n=6, p<0.01, F=28.37$, DFn = 1, DFd = 50; ZnT3KO mice: control: $50 \mathrm{~Hz}: 1.71 \pm 0.27$ vs. ZX1: $1.74 \pm 0.33, n=5, p=0.85, F=0.04$, DFn = 1, DFd $=40$; two-way ANOVA. $\boldsymbol{H}$, lower panel: ratio of the amplitude of 16-20 EPSC to first EPSC: ZnTWT vs. ZnT3KO: control: $50 \mathrm{~Hz}: 5.58 \pm 0.39$ vs. $1.71 \pm 0.27, n=5, p<0.01$, $t=8.15, \mathrm{df}=8$; unpaired $t$-test.

showing that fewer stimuli are needed to elicit endocannabinoid signaling during higher stimulation frequencies (compare Fig. 5A and Fig. 6E), we expect that higher stimulation frequencies would also require fewer stimuli for eliciting the enhancing effect of zinc on steady-state EPSCs. Therefore, given the strong resemblance between DCN and cerebellar granule cells (Oertel and Young, 2004), we hypothesize that the effect of zinc in maintaining enhanced synaptic facilitation during bursts of activity may enhance information flow in cartwheel cells. However, because our in vitro stimulation may be stronger than the in vivo pattern of activity, further in vivo studies using natural stimuli are required to determine how synaptic zinc affects information coding in the molecular layer of the DCN.

We previously reported that synaptically released zinc decreases post-tetanic potentiation induced by highfrequency stimulation (Perez-Rosello et al., 2013); how-

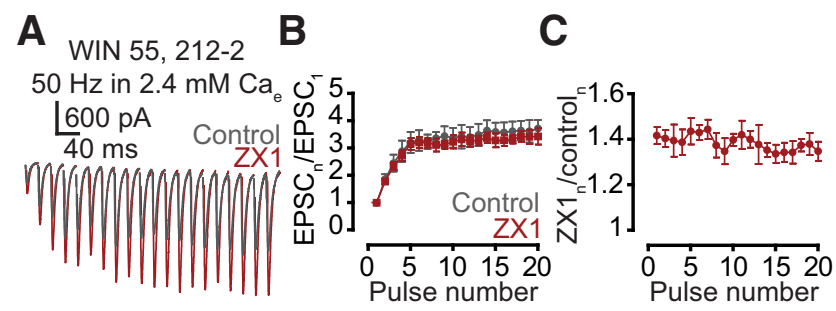

Figure 7. The postsynaptic inhibitory effect of zinc on AMPA EPSC does not contribute to the zinc-mediated enhancement of synaptic facilitation. $\boldsymbol{A}$, Representative traces of AMPA EPSCs, evoked by $50-\mathrm{Hz} 20$-pulse train in the presence of 50 nM WIN 55 212-2, before (gray) and after (maroon) ZX1. B, Summary graph showing average AMPA EPSC amplitudes during the train, normalized to EPSC amplitude elicited by the first pulse, before (gray) and after (maroon) ZX1 (ratio of the amplitude of 16-20 EPSC to first EPSC at $50 \mathrm{~Hz}$ : control vs. ZX1, $n=5, p=0.18$ ). $C$, Summary graph showing average ratios of AMPA EPSCs in the presence of $Z X 1$ to that in control during the train $\left(Z X_{1-2} /\right.$ control $_{1-2}$ vs. $Z_{16-20}$ control $\left._{16-20}, n=5, p=0.23\right)$. Values represent mean \pm SEM.

Detailed values and statistical tests: $\boldsymbol{B}$, Ratio of the amplitude of 16-20 EPSC to first EPSC at $50 \mathrm{~Hz}$ : control: $3.63 \pm 0.35$ vs. ZX1: $3.23 \pm 0.22, n=5, p=0.18, F=1.84$, DFn $=1$, DFd $=40$; two-way ANOVA; $\boldsymbol{C}, \mathrm{ZX}_{1-2} /$ control $_{1-2}$ vs. $\mathrm{ZX}_{16-20}$ control $_{16-20}$ : $1.40 \pm 0.04$ vs. $1.35 \pm 0.05, n=5, p=0.23, t=1.39$, df $=4$, paired $t$-test. ever, the effect of zinc during the high-frequency stimulation had not been studied. By assessing the role of synaptically released zinc during low- and high-frequency trains, we found that synaptic strength at intensely active synapses is larger under conditions that inhibit $\mathrm{Pr}$, such as zinc-dependent endocannabinoid signaling. These results complement and extend previous studies on presynaptic $\mathrm{GABA}_{\mathrm{B}}$ receptors, which sustain neurotransmission at higher stimulus frequencies by reducing $\operatorname{Pr}$ and, in turn, controlling AMPAR desensitization (Brenowitz et al., 1998; Brenowitz and Trussell, 2001). Whereas zinc and GABA receptors exert their context-dependent effects via different mechanisms, a common concept emerges supporting that neuromodulatory systems that combine pre- and postsynaptic mechanisms of actions also display a unique flexibility in mediating bidirectional modulation of EPSC strength (Tzounopoulos et al., 2007).

Our findings on zinc-mediated promotion of endocannabinoid signaling are consistent with our previous report showing that during high-frequency stimulation synaptic zinc release, activation of GPR39 receptors and subsequent rises in postsynaptic calcium and phospholipase $\mathrm{C}$ activation are necessary for triggering the synthesis of the endocannabinoid 2-arachidonoylglycerol in PF DCN synapses (Perez-Rosello et al., 2013). Moreover, the lack of zinc-dependent enhancement in EPSC $_{S S}$ during lower stimulation frequencies, as well as the development of the endocannabinoid-mediated effect later in the train during high-frequency stimulation, are consistent with the notion that endocannabinoid signaling in DCN synapses is recruited in response to sustained high-frequency bursts of neuronal activity (Sedlacek et al., 2011; Perez-Rosello et al., 2013).

Prior studies have reported a lack of effect of synaptic zinc on short-term synaptic plasticity of AMPA EPSCs in zinc-rich hippocampal mossy fiber to CA3 (MF-CA3) or Schaffer collateral to CA1 (SC-CA1) synapses (Vogt et al., 2000; Vergnano et al., 2014). The lack of effect in these studies could be because the investigated synapses lack or express weak endocannabinoid signaling (OhnoShosaku et al., 2002; Hofmann et al., 2008). Moreover, these studies used a narrower range of stimulation frequencies that did not exceed $25 \mathrm{~Hz}$. This could also explain the lack of effect of zinc on short-term plasticity, because higher or more sustained stimulation frequencies 
are required for the recruitment of endocannabinoid signaling (Perez-Rosello et al., 2013), which, in turn, is crucial for the effects of zinc on short-term plasticity of glutamatergic neurotransmission. Finally, although these studies used ZnT3KO mice to eliminate synaptic zinc, zinc was chelated with tricine or CaEDTA. However, CaEDTA has slower kinetics for zinc binding than ZX1, and tricine has weaker zinc-binding affinity than ZX1 (Anderson et al., 2015). Therefore, CaEDTA and tricine are less efficient than ZX1 for investigating the effects of fast, transient elevations of synaptic zinc on synaptic targets, such as NMDAR and AMPARs (Anderson et al., 2015; Kalappa et al., 2015). Together, these data suggest that the context-dependent effect of zinc on glutamatergic neurotransmission is synapse specific and, like the effects of other neuromodulatory systems, depends on the molecular composition, structure, and function of different synapses.

Recent studies explored the dynamics of zinc in the synaptic cleft and extracellular space (Vergnano et al., 2014; Anderson et al., 2015), but less is known about the presynaptic zinc dynamics. Whereas one study suggests that zinc-containing vesicles predominantly dominate the reserve pool of synaptic vesicles (Lavoie et al., 2011), the exocytosis and endocytosis dynamics of zinc-containing vesicles remain unknown. Our results are inconsistent with depletion of zinc-containing vesicles during the highfrequency train, for $Z X 1$ revealed no change in the amount of AMPA EPSC potentiation throughout the train of stimuli in the presence of exogenously applied cannabinoids (Fig. 7). This conclusion is based on the assumption that zincmediated AMPA EPSC inhibition tracks synaptic zinc levels in the cleft. However, recent results proposed AMPA EPSC modulation via intracellular zinc signaling in cultured hippocampal neurons (Arons et al., 2016). As such, transient increases in extracellular zinc after synaptic stimulation could lead to translocation of zinc into the postsynaptic neuron via zinc-permeable AMPARs (Jia et al., 2002), inducing, in turn, changes in intracellular zinc levels and modulation of AMPA EPSCs that does not track extracellular zinc levels. NMDARs contain extracellular high-affinity binding sites capable of tracking extracellular zinc levels (Paoletti et al., 2009; Hansen et al., 2014), and therefore future studies assessing the effect of synaptic zinc on NMDARs, or using localized extracellular zinc-sensitive dyes to quantify zinc levels during trains of presynaptic activity, are needed for elucidating the time course of exocytosis and endocytosis of zinc-containing vesicles.

In summary, this work demonstrates that during highfrequency trains of presynaptic activity, synaptic zinc scales glutamatergic neurotransmission bidirectionally. During the onset of activity, glutamatergic neurotransmission is scaled down predominantly by postsynaptic zinc inhibition; however, later in the train, zinc-dependent endocannabinoid signaling decreases $\operatorname{Pr}$, which, in turn, increases synaptic facilitation. This enhancement overrides the $\operatorname{Pr}$ decrease and postsynaptic zinc inhibitory effects, thus resulting in overall enhanced synaptic strength.

\section{References}

Abbott LF, Regehr WG (2004) Synaptic computation. Nature 431, 796-803. CrossRef Medline

Anderson CT, Radford RJ, Zastrow ML, Zhang DY, Apfel UP, Lippard SJ, Tzounopoulos T (2015) Modulation of extrasynaptic NMDA receptors by synaptic and tonic zinc. Proc Natl Acad Sci U S A 112, E2705-E2714. CrossRef Medline

Arons MH, Lee K, Thynne CJ, Kim SA, Schob C, Kindler S, Montgomery JM, Garner CC (2016) Shank3 is part of a zinc-sensitive signaling system that regulates excitatory synaptic strength. J Neurosci 36, 9124-9134. CrossRef

Brenowitz S, David J, Trussell L (1998) Enhancement of synaptic efficacy by presynaptic GABA(B) receptors. Neuron 20, 135-141. Medline

Brenowitz S, Trussell LO (2001) Minimizing synaptic depression by control of release probability. J Neurosci 21, 1857-1867. Medline

Chadderton P, Margrie TW, Häusser M (2004) Integration of quanta in cerebellar granule cells during sensory processing. Nature 428 , 856-860. CrossRef Medline

Chen C, Blitz DM, Regehr WG (2002) Contributions of receptor desensitization and saturation to plasticity at the retinogeniculate synapse. Neuron 33, 779-788. Medline

Cole TB, Wenzel HJ, Kafer KE, Schwartzkroin PA, Palmiter RD (1999) Elimination of zinc from synaptic vesicles in the intact mouse brain by disruption of the ZnT3 gene. Proc Natl Acad Sci U S A, 96, 1716-1721. CrossRef

Foster KA, Kreitzer AC, Regehr WG (2002) Interaction of postsynaptic receptor saturation with presynaptic mechanisms produces a reliable synapse. Neuron 36, 1115-1126. CrossRef

Frederickson CJ, Howell GA, Haigh MD, Danscher G (1988) Zinccontaining fiber systems in the cochlear nuclei of the rat and mouse. Hear Res 36, 203-211. CrossRef

Frederickson CJ, Koh JY, Bush Al (2005) The neurobiology of zinc in health and disease. Nature Rev Neurosci 6, 449-462. CrossRef Medline

Hansen KB, Ogden KK, Yuan H, Traynelis SF (2014) Distinct functional and pharmacological properties of triheteromeric GluN1/ GluN2A/GluN2B NMDA receptors. Neuron 81, 1084-1096. CrossRef Medline

Hofmann ME, Nahir B, Frazier CJ (2008) Excitatory afferents to CA3 pyramidal cells display differential sensitivity to CB1 dependent inhibition of synaptic transmission. Neuropharmacology 55, 1140 1146. CrossRef

Jackman SL, Turecek J, Belinsky JE, Regehr WG (2016) The calcium sensor synaptotagmin 7 is required for synaptic facilitation. Nature 529, 88-91. CrossRef Medline

Jia Y, Jeng JM, Sensi SL, Weiss JH (2002) Zn2+ currents are mediated by calcium-permeable AMPA/kainate channels in cultured murine hippocampal neurones. J Physiol 543, 35-48. CrossRef

Kalappa BI, Anderson CT, Goldberg JM, Lippard SJ, Tzounopoulos T (2015) AMPA receptor inhibition by synaptically released zinc. Proc Natl Acad Sci U S A 112, 15749-15754. CrossRef Medline

Kelleher SL, McCormick NH, Velasquez V, Lopez V (2011) Zinc in specialized secretory tissues: roles in the pancreas, prostate, and mammary gland. Adv Nutr 2, 101-111. CrossRef

Kreitzer AC, Regehr WG (2000) Modulation of transmission during trains at a cerebellar synapse. J Neurosci 20, 1348-1357. Medline

Kreitzer AC, Regehr WG (2002) Retrograde signaling by endocannabinoids. Curr Opin Neurobiol 12, 324-330. Medline

Lan R, Liu Q, Fan P, Lin S, Fernando SR, McCallion D, Pertwee R, Makriyannis A (1999) Structure-activity relationships of pyrazole derivatives as cannabinoid receptor antagonists. J Med Chem 42, 769-776. CrossRef

Lavoie N, Jeyaraju DV, Peralta MR 3rd, Seress L, Pellegrini L, Toth K (2011) Vesicular zinc regulates the Ca2 + sensitivity of a subpopulation of presynaptic vesicles at hippocampal mossy fiber terminals. J Neurosci 31, 18251-18265. CrossRef 
Lisman JE (1997) Bursts as a unit of neural information: making unreliable synapses reliable. Trends Neurosci 20, 38-43. CrossRef Medline

Manis PB, Spirou GA, Wright DD, Paydar S, Ryugo DK (1994) Physiology and morphology of complex spiking neurons in the guinea pig dorsal cochlear nucleus. J Compar Neurol 348, 261276. CrossRef

Neher E, Sakaba T (2001) Combining deconvolution and noise analysis for the estimation of transmitter release rates at the calyx of held. J Neurosci 21, 444-461. Medline

Oertel D, Young ED (2004) What's a cerebellar circuit doing in the auditory system? Trends Neurosci 27, 104-110. CrossRef Medline

Ohno-Shosaku T, Tsubokawa H, Mizushima I, Yoneda N, Zimmer A, Kano M (2002) Presynaptic cannabinoid sensitivity is a major determinant of depolarization-induced retrograde suppression at hippocampal synapses. J Neurosci 22, 3864-3872.

Pan E, Zhang XA, Huang Z, Krezel A, Zhao M, Tinberg CE, Lippard SJ, McNamara JO (2011) Vesicular zinc promotes presynaptic and inhibits postsynaptic long-term potentiation of mossy fiber-CA3 synapse. Neuron 71, 1116-1126. CrossRef

Paoletti P, Vergnano AM, Barbour B, Casado M (2009) Zinc at glutamatergic synapses. Neuroscience 158, 126-136. CrossRef Medline

Partin KM, Fleck MW, Mayer ML (1996) AMPA receptor flip/flop mutants affecting deactivation, desensitization, and modulation by cyclothiazide, aniracetam, and thiocyanate. J Neurosci 16, 6634-6647.

Partin KM, Patneau DK, Mayer ML (1994) Cyclothiazide differentially modulates desensitization of alpha-amino-3-hydroxy-5-methyl-4isoxazolepropionic acid receptor splice variants. Mol Pharmacol 46, 129-138.

Perez-Rosello T, Anderson CT, Schopfer FJ, Zhao Y, Gilad D, Salvatore SR, Freeman BA, Hershfinkel M, Aizenman E, Tzounopoulos T (2013) Synaptic Zn2+ inhibits neurotransmitter release by promoting endocannabinoid synthesis. J Neurosci 33, 9259-9272. CrossRef

Prescott C, Weeks AM, Staley KJ, Partin KM (2006) Kynurenic acid has a dual action on AMPA receptor responses. Neurosci Lett 402, 108-112. CrossRef Medline
Sedlacek M, Tipton PW, Brenowitz SD (2011) Sustained firing of cartwheel cells in the dorsal cochlear nucleus evokes endocannabinoid release and retrograde suppression of parallel fiber synapses. J Neurosci 31, 15807-15817. CrossRef

Sindreu CB, Varoqui H, Erickson JD, Pérez-Clausell J (2003) Boutons containing vesicular zinc define a subpopulation of synapses with low AMPAR content in rat hippocampus. Cereb Cortex 13, 823829. Medline

Trussell LO, Zhang S, Raman IM (1993) Desensitization of AMPA receptors upon multiquantal neurotransmitter release. Neuron 10, 1185-1196. Medline

Tzounopoulos T, Kim Y, Oertel D, Trussell LO (2004) Cell-specific, spike timing-dependent plasticities in the dorsal cochlear nucleus. Nature Neurosci 7, 719-725. CrossRef

Tzounopoulos, T Rubio ME, Keen JE, Trussell LO (2007) Coactivation of pre- and postsynaptic signaling mechanisms determines cellspecific spike-timing-dependent plasticity. Neuron 54, 291-301. CrossRef

Vallee BL (1988) Zinc: biochemistry, physiology, toxicology and clinical pathology. Biofactors 1, 31-36. Medline

Vergnano AM, Rebola N, Savtchenko LP, Pinheiro PS, Casado M, Kieffer BL, Rusakov DA, Mulle C, Paoletti P (2014) Zinc dynamics and action at excitatory synapses. Neuron 82, 1101-1114. CrossRef Medline

Vogt K, Mellor J, Tong G, Nicoll R (2000) The actions of synaptically released zinc at hippocampal mossy fiber synapses. Neuron 26 , 187-196. Medline

Wadiche JI, Jahr CE (2001) Multivesicular release at climbing fiberPurkinje cell synapses. Neuron 32, 301-313. Medline

Wilson RI, Nicoll RA (2002) Endocannabinoid signaling in the brain. Science 296, 678-682. CrossRef Medline

Zhang S, Oertel D (1993) Cartwheel and superficial stellate cells of the dorsal cochlear nucleus of mice: intracellular recordings in slices. J Neurophysiol 69, 1384-1397.

Zucker RS, Regehr WG (2002) Short-term synaptic plasticity. Annu Rev Physiol 64, 355-405. CrossRef Medline 